\title{
Rest contrast echocardiography unmasks hidden wall motion abnormalities in patients with chest pain. A case series and review of pertinent literature.
}

\author{
Sergio Suma ${ }^{1}$, Domenico Tuttolomondo ${ }^{2}$, and Nicola Gaibazzi ${ }^{2}$ \\ ${ }^{1}$ Azienda Ospedaliero Universitaria di Parma \\ ${ }^{2}$ Azienda Ospedaliero-Universitaria di Parma
}

July 26, 2021

\begin{abstract}
We present a case series of three patients that underwent myocardial contrast echocardiography (MCE) in the setting of recent chest pain, as paradigmatic examples of the usefulness of contrast-echocardiography with very-low mechanical index imaging in the context of rest wall motion assessment. Moreover, we analysed the pertinent literature about the use of rest MCE in the context of chest pain of unknown origin, showing its diagnostic and prognostic impact. We think that MCE could play a key role in detecting chest pain subtended by previously unknown CAD. For example, in pts without significant ECG modifications or in whom high sensitivity troponins show only borderline increase (still below the upper limit) or have no clearly significant delta. In such cases the more sensitive evaluation of WM powered by MCE could add diagnostic information, above all in pts with severe CAD but apparently normal WM at standard echocardiography.
\end{abstract}

\section{TITLE PAGE}

Rest contrast echocardiography unmasks hidden wall motion abnormalities in patients with chest pain. A case series and review of pertinent literature.

Sergio Suma MD ${ }^{1}$, Domenico Tuttolomondo $\mathrm{MD}^{1}$, Nicola Gaibazzi MD PhD ${ }^{1}$

Cardiology Department, University Hospital of Parma, Italy

\section{Corresponding Author}

Sergio Suma MD

sergiosuma.md@gmail.com

ph +393202836383

ORCID https://orcid.org/0000-0002-0018-4669

\section{ABSTRACT}

We present a case series of three patients that underwent myocardial contrast echocardiography (MCE) in the setting of recent chest pain, as paradigmatic examples of the usefulness of contrast-echocardiography with very-low mechanical index imaging in the context of rest wall motion assessment.

Moreover, we analysed the pertinent literature about the use of rest MCE in the context of chest pain of unknown origin, showing its diagnostic and prognostic impact. 
We think that MCE could play a key role in detecting chest pain subtended by previously unknown CAD. For example, in pts without significant ECG modifications or in whom high sensitivity troponins show only borderline increase (still below the upper limit) or have no clearly significant delta. In such cases the more sensitive evaluation of WM powered by MCE could add diagnostic information, above all in pts with severe CAD but apparently normal WM at standard echocardiography.

\section{CASES PRESENTATION}

In this case series we present three patients (pts) that underwent myocardial contrast echocardiography (MCE) in the setting of recent chest pain, as paradigmatic examples of the usefulness of contrastechocardiography with very-low mechanical index imaging in the context of rest wall motion assessment.

The first patient was a 57 years old man with no cardiovascular risk factors who presented to the emergency department (ED) due to chest pain on effort and also at rest. The ECG showed mild abnormalities on the anterior leads, and there was a mild increase of the troponin I levels. At transthoracic echocardiography (TTE) left ventricular wall motion (WM) was apparently normal with no regional abnormalities.

The second patient was a 40-year-old man with hypercholesterolemia who had chest pain on effort and again also at rest. In this case the ECG was unremarkable and the high sensitivity troponin I was between the limit of detection (LOD) and upper reference limit (URL) with no significant delta between two serial measurements. Again, at TTE there was an apparently normal segmental WM of the left ventricle.

Last patient was a 58-year-old woman with obesity and hypertension who was evaluated at the outpatients clinic for exertional chest pain with few episodes at rest. The ECG was unremarkable and the troponin was not measured at that time. TTE was apparently normal also in this case.

Since the symptoms were very typical in all the three cases and the suspect of coronary artery disease (CAD) was high, we integrated the TTE with contrast administration for better WM assessment. In all the cases, the more accurate evaluation of endocardial border could reveal WM abnormalities in the LAD territory: in particular, in case 1 they involved the anterior mid-to-distal wall, the apex and the distal septum (see figure 1 for details, and video 1 and 2), in case 2 the distal anterior wall, the apex and the distal septum (see figure 2 and video 3 and 4), in case 3 the mid-to-distal septum, the apex and the latero-apical wall (see figure 3 and video 5 and 6 ).

Moreover, even if the use of small boluses of contrast is not ideal for the study of myocardial perfusion $(\mathrm{MP})$, the assessment of WM using real-time very low mechanical index $(<0.2)$ provides collateral information regarding MP, which was reduced in these cases and further contributed to highlight the subtle WM abnormalities.

All the three-pts had severe left anterior descending coronary artery (LAD) stenosis which turned out to be sub-occlusive in all of the three pts. The first two pts underwent coronary angiography (figure 4 and 5), whereas the last patient underwent computed tomography (figure 6 and video 7 ) and will soon undergo coronary angiography as well.

\section{REVIEW OF THE PUBLISHED LITERATURE WITH MCE USED FOR WALL MOTION EVALUATION}

The use of rest MCE in the context of chest pain was evaluated in different studies either or both for WM and MP assessments. The studies that evaluated only MP were not included in our review.

Rinkevich et al. ${ }^{1}$ studied the MCE in predicting events in pts with CP who presented to the ED with non ST-elevation at the ECG; in particular they analysed 1017 pts, assessing both regional WM and MP with MCE in addition to the standard ECG evaluation, with a mean follow-up of 7.7 months. Considering only rest WM data, which is the main purpose of the current review, 43 pts with normal WM had events and 249 events (85\% of all events) took place in patients with rest WM abnormalities assessed with contrast.

On the multivariable Cox regression analysis, history of hypertension $(\mathrm{P}=0.028)$, ECG $(\mathrm{P}=0.0001)$, WM 
$(\mathrm{P}<0.0001)$, and MP $(\mathrm{P}<0.0001)$ were significant predictors of cardiac events. Abnormal WM increased the risk of events by five-fold when compared with normal WM (95\% CI: 3.4-7.2), whereas abnormal MP increased the risk by only twofold

when compared with normal MP (95\% CI: 1.5-2.7).

They concluded that early assessment of WM (and MP) on MCE added significant diagnostic and prognostic value to routine evaluation in pts presenting to the ED with suspected cardiac CP and no ST-segment elevation. There was no standard (without contrast) echocardiography included in the standard clinical comparison control, so that MCE for rest WM assessment was compared to clinical assessment and ECG only. Furthermore, Troponin assessment was not included in the study.

Tong et al. ${ }^{2}$ compared WM and MP analysis with modified TIMI risk score (mTIMI, which is TIMI score not including troponin levels) in $957 \mathrm{pts}$ presenting to the ED with CP and a nondiagnostic ECG. Cumulative pts outcomes were determined at three time points: early (within 24 hours), intermediate (up to 30 days), and late (>30 days). On the basis of their mTIMI or TIMI scores, pts were categorized as either low $($ score $<2)$, intermediate (score of 3 or 4 ), or high (score $>5$ ) risk. The mTIMI score was unable to discriminate between intermediate- compared to high-risk pts at any follow-up time point, whereas only 2 of $523 \mathrm{pts}$ with normal WM had an early primary event. WM evaluation provided incremental prognostic value over mTIMI scores for predicting intermediate and late events. But it should be emphasized that rest MCE WM was not assessed with very low mechanical index imaging but rather with harmonic low mechanical index, which has lower yield to detect WM abnormalities compared with very low mechanical index imaging. The full TIMI score could not improve upon these results at any follow-up time point.

Wei et al. ${ }^{3}$ enrolled 1166 pts (cohort 1) with a validation cohort (cohort 2) of 720 pts; all pts presented to ED with CP lasting 30 minutes or more and there wasn't any ST-segment elevation on the ECG. Wall motion (WM) and myocardial perfusion (MP) were separately assessed by MCE. Any abnormality or ST changes on ECG (odds ratio [OR] 2.5; 95\% confidence interval [CI] 1.4-4.5, P $=0.002$, and OR 2.9, 95\% CI, 1.7-4.8, P < 0.001, respectively), abnormal WM with normal MP (OR 3.5, 95\% CI, 1.8-6.5, P < 0.001), and abnormal WM with abnormal MP (OR 9.6, 95\% CI, 5.8-16.0, P < 0.001), so that either or both WM and MP were found to be significant multivariate predictors of nonfatal myocardial infarction or cardiac death. Apparently, there was no comparison between WM assessed with MCE and without contrast, so that in this well-conducted study, there remains the clinical question whether contrast WM assessment is superior or not to standard WM assessment without contrast.

Kalvaitis et al. ${ }^{4}$ explored the effect of time delay of the use of MCE in the ED. In particular 957 pts were enrolled, they presented to ED with CP and no ST-elevation at the ECG and were divided into 4 quartiles depending on the time between their last episode of $\mathrm{CP}$ and the MCE evaluation. Pts in quartile I had MCE during ongoing CP (time delay of 0 minutes). The time delays in quartiles II, III, and IV were $54 \pm$ $44,213 \pm 54$, and $556 \pm 184$ minutes, respectively $(\mathrm{P}<0.001)$. In each quartile, pts with normal WM had the lowest incidence of events, whereas those with both abnormal WM and MP had the highest incidence of events. Pts with abnormal WM but normal MP had an intermediate event rate. They concluded that timing of MCE did not affect the ability to predict event rate at 24 hours in pts with CP. Again, it should be emphasized that rest MCE WM was not assessed with very low mechanical index imaging but rather with harmonic low mechanical index, which has lower capability to detect WM abnormalities compared with very low mechanical index imaging.

Wyrick et al. ${ }^{5}$ analysed the cost-efficiency of MCE in 957 pts presenting to ED with CP and no ST-elevation at the ECG, but this analysis is most probably conducted on the same patient cohort studied by Kalvaitis et $\mathrm{al},{ }^{4}$ so we did not include it in our review.

Finally, Porter et al. ${ }^{6}$ compared patient outcome after stress real-time MCE (RTMCE), using very-low mechanical index, versus conventional stress echo with low mechanical index and harmonic imaging (CSE). Outpatient and inpatient subjects admitted for chest pain with normal or equivocal troponin were referred for dobutamine or exercise stress echocardiography were prospectively randomized to either RTMCE or 
CSE. Definity contrast was used for CSE only when endocardial border delineation was inadequate (63\% of studies). 2014 pts were evaluated with a mean follow-up of 2.6 years. An abnormal RTMCE was more frequently observed than an abnormal CSE at peak stress $(\mathrm{p}<0.001)$, and more frequently resulted in revascularization $(\mathrm{p}=0.004)$. Resting WM abnormalities were also more frequently seen with RTMCE $(\mathrm{p}<$ $0.01)$, and were an independent predictor of death/nonfatal MI ( $\mathrm{p}=0.005)$ for RTMCE, but not CSE. This is a signal that RTMCE, as now supported by European and American guidelines, ${ }^{7,8}$ is superior to standard contrast-echocardiography-using higher mechanical index (0.2-0.4) and harmonic imaging- to detect mild WM abnormalities.

\section{DISCUSSION}

Contrast agents in conjunction with very low MI contrast real-time imaging increase the accuracy of WM assessment, both through endocardial border enhancement and by simultaneously providing collateral information on MP (MP defects always precede WM abnormalities), which in turns enhances the visual capability to detect a WM abnormality, if present. This can be particularly helpful in cases of poor acoustic windows, as well as in cases of difficult evaluation of the anterior wall and of the apex. In this not-unusual context, MCE could be of great interest in the routine evaluation of wall motion in pts with chest pain of uncertain origin.

In fact, the importance and usefulness of MCE for better rest WM assessment in the evaluation of CP has been only partially demonstrated in the studies reported above, in terms of risk stratification, diagnostic and prognostic impact as well as cost-efficiency. Most such studies were actually performed several years ago, most were single-centre, most used echocardiography machines not anymore commercially available (as it is also the case for the contrast media used) and they used impractical long continuous infusion of contrast. Furthermore, no study compared the usefulness of an enhanced evaluation of WM by MCE with the standard evaluation of WM by standard echocardiography (with no contrast), which is probably the most compelling practical clinical issue.

This could be of great interest in the context of the ED for the evaluation of CP of unknown origin, even in the current era of high-sensitivity troponins.

Indeed, we think that there remain many grey-cases in the daily routine practice, in which MCE could play a key role in detecting chest pain subtended by previously unknown CAD. For example, in pts without significant ECG modifications or in whom high sensitivity troponins show only borderline increase (still below the upper limit) or have no clearly significant delta. In such cases the more sensitive evaluation of WM powered by MCE could add diagnostic information, above all in pts with severe CAD but apparently normal WM at standard echocardiography.

In conclusion, more and contemporary studies are warranted to confirm the usefulness of MCE in pts with $\mathrm{CP}$ despite the availability of high sensitivity troponins; as shown in the reported cases, we believe that $\mathrm{MCE}$, through the detection of otherwise apparently and falsely normal WM could play an important role in the detection of underlying $\mathrm{CAD}$ as a cause of acute/subacute $\mathrm{CP}$ admitted to the ED.

\begin{tabular}{|c|c|c|c|c|c|c|c|}
\hline Study/Year & $\begin{array}{l}\mathrm{N}^{\circ} \\
\text { patients }\end{array}$ & Setting & $\begin{array}{l}\text { Contrast } \\
\text { agent }\end{array}$ & $\begin{array}{l}\text { Contrast } \\
\text { Infusion } \\
\text { modality }\end{array}$ & $\begin{array}{l}\text { Contrast } \\
\text { echo } \\
\text { modality } \\
\text { for wall } \\
\text { motion }\end{array}$ & $\begin{array}{l}\text { WM } \\
\text { and/or } \\
\text { MP eval- } \\
\text { uation }\end{array}$ & Comparator $/ 1$ \\
\hline $\begin{array}{l}\text { Rinkevich } \\
\text { et al. - } \\
2005\end{array}$ & 1017 & $\mathrm{CP}$ & Optison & $\begin{array}{l}\text { Continuous } \\
\text { infusion }\end{array}$ & $\begin{array}{l}\text { Real-time } \\
\mathrm{MI}<0.3\end{array}$ & $\begin{array}{l}\text { WM and } \\
\text { MP }\end{array}$ & MACE \\
\hline
\end{tabular}




\begin{tabular}{|c|c|c|c|c|c|c|c|}
\hline Study/Year & $\begin{array}{l}\mathrm{N}^{\circ} \\
\text { patients }\end{array}$ & Setting & $\begin{array}{l}\text { Contrast } \\
\text { agent }\end{array}$ & $\begin{array}{l}\text { Contrast } \\
\text { Infusion } \\
\text { modality }\end{array}$ & $\begin{array}{l}\text { Contrast } \\
\text { echo } \\
\text { modality } \\
\text { for wall } \\
\text { motion }\end{array}$ & $\begin{array}{l}\text { WM } \\
\text { and/or } \\
\text { MP eval- } \\
\text { uation }\end{array}$ & Comparator $/ \mathbf{I}$ \\
\hline $\begin{array}{l}\text { Tong et } \\
\text { al. - } \\
2005\end{array}$ & 957 & $\mathrm{CP}$ & Optison & $\begin{array}{l}\text { Continuous } \\
\text { infusion }\end{array}$ & $\begin{array}{l}\text { Real-time } \\
\text { harmonic } \\
\text { unknown } \\
\text { MI }\end{array}$ & $\begin{array}{l}\text { WM and } \\
\text { MP }\end{array}$ & $\begin{array}{l}\text { mTIMI } \\
\text { score }\end{array}$ \\
\hline $\begin{array}{l}\text { Wei et al. } \\
-2010\end{array}$ & 1166 & $\mathrm{CP}$ & Optison & $\begin{array}{l}\text { Continuous } \\
\text { infusion }\end{array}$ & $\begin{array}{l}\text { Real-time } \\
\mathrm{MI}<0.3\end{array}$ & $\begin{array}{l}\text { WM and } \\
\text { MP }\end{array}$ & MACE \\
\hline $\begin{array}{l}\text { Kalvaitis } \\
\text { et al. - } \\
2006\end{array}$ & 957 & $\mathrm{CP}$ & Optison & $\begin{array}{l}\text { Continuous } \\
\text { infusion }\end{array}$ & $\begin{array}{l}\text { Real-time } \\
\mathrm{MI}<0.3\end{array}$ & $\begin{array}{l}\text { WM and } \\
\text { MP }\end{array}$ & Time/MACE \\
\hline $\begin{array}{l}\text { Porter et } \\
\text { al. }-2013\end{array}$ & 2014 & $\mathrm{CP}$ & Definity & $\begin{array}{l}\text { Continuous } \\
\text { infusion }\end{array}$ & $\begin{array}{l}\text { Both } \\
\text { real-time } \\
\mathrm{MI}<0.2 \text { and } \\
\text { real-time } \\
\text { harmonic } \\
\text { higher MI }\end{array}$ & $\begin{array}{l}\text { WM and } \\
\text { MP }\end{array}$ & MACE \\
\hline
\end{tabular}

Tab 1. ACS Acute Coronary Syndrome; CP Chest pain of unknow origin with no ST-segment elevation at the ECG; MI mechanical index; WM wall motion; MP myocardial perfusion; MACE Major adverse cardiovascular events.

FIGURE

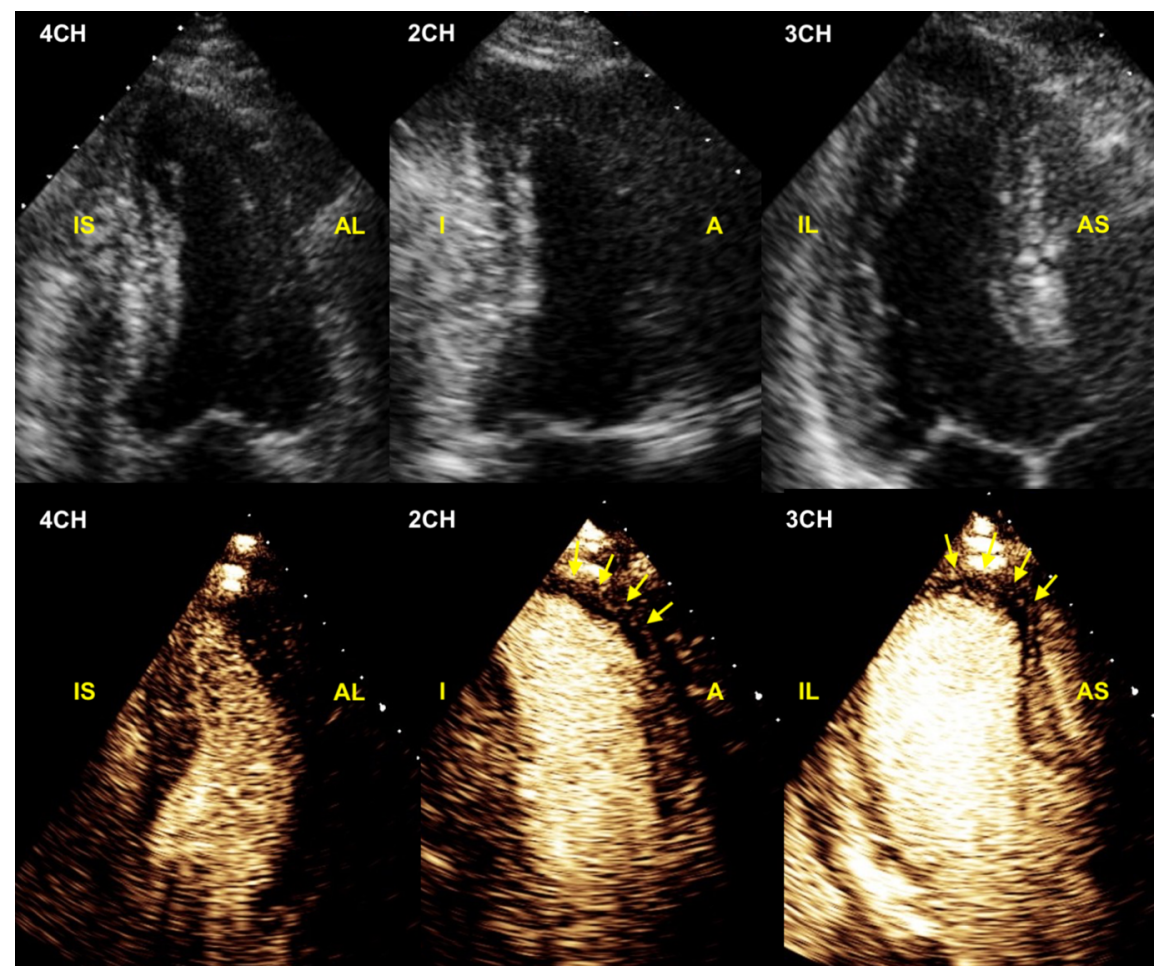


Figure 1. TTE of patient 1 comparing standard views (at the top) with MCE (below). MCE shows WM and MP abnormalities in the anterior mid-to-distal wall, the apex and the distal septum (see arrows). $4 \mathrm{CH}$ 4-chambers view; $2 \mathrm{CH}$ 2-chambers view; $3 \mathrm{CH}$ 3-chambers view; IS Infero-septal wall; AL antero-lateral wall; I Inferior wall; A Anterior wall; IL infero-lateral wall; AS antero-septal wall.

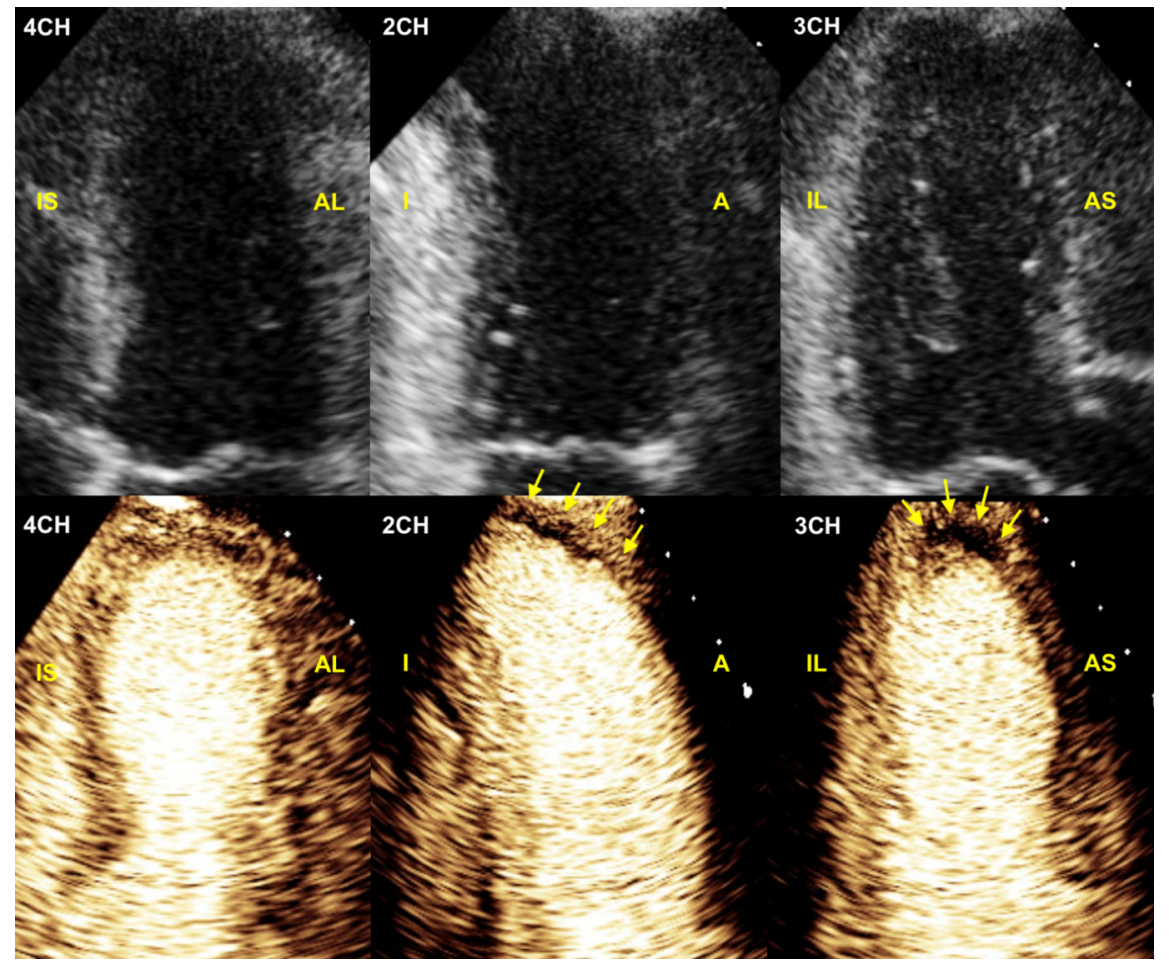

Figure 2. TTE of patient 1 comparing standard views (at the top) with MCE (below). MCE shows WM and MP abnormalities in distal anterior wall, the apex and the distal septum (see arrows). 4CH 4-chambers view; $2 \mathrm{CH}$ 2-chambers view; $3 \mathrm{CH}$ 3-chambers view; IS Infero-septal wall; AL antero-lateral wall; I Inferior wall; A Anterior wall; IL infero-lateral wall; AS antero-septal wall. 


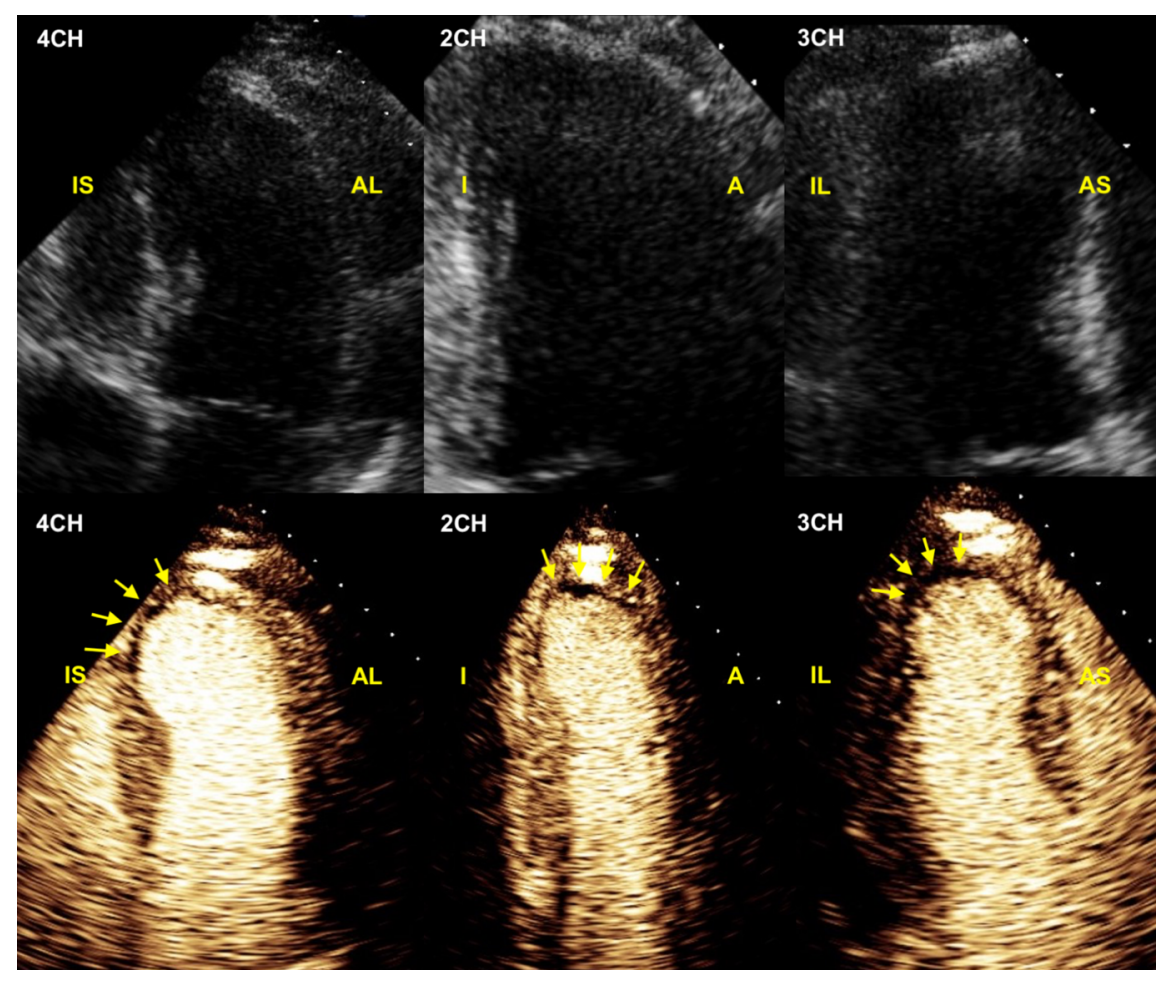

Figure 3. TTE of patient 1 comparing standard views (at the top) with MCE (below). MCE shows WM and MP abnormalities in the mid-to-distal septum, the apex and the latero-apical wall (see arrows). $4 \mathrm{CH}$ 4-chambers view; $2 \mathrm{CH}$ 2-chambers view; $3 \mathrm{CH}$ 3-chambers view; IS Infero-septal wall; AL antero-lateral wall; I Inferior wall; A Anterior wall; IL infero-lateral wall; AS antero-septal wall. 


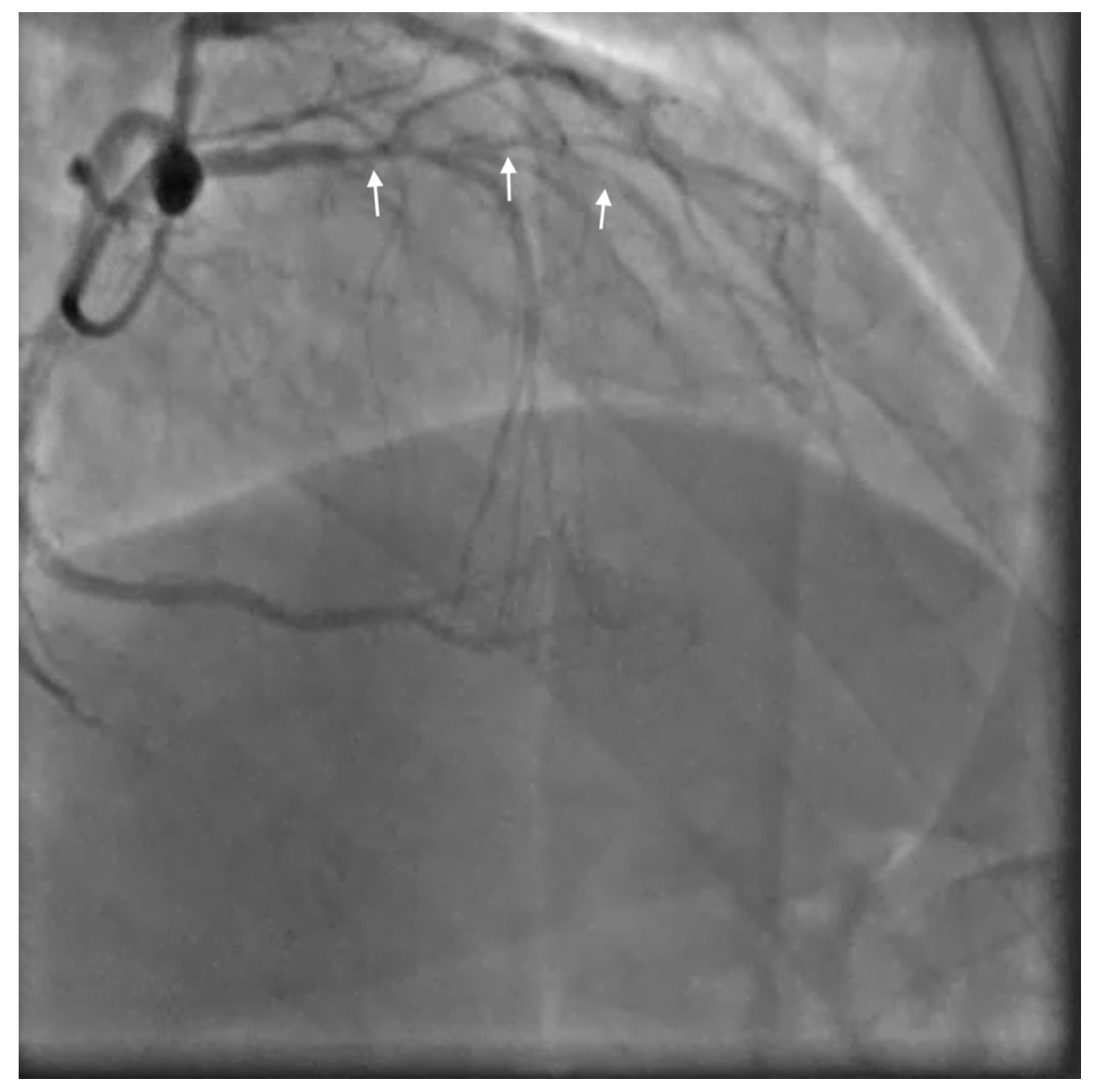

Figure 4. Coronary Angiogram in patient 1 showing severe sub-occlusive multiple stenosis (arrows) in the LAD course. 


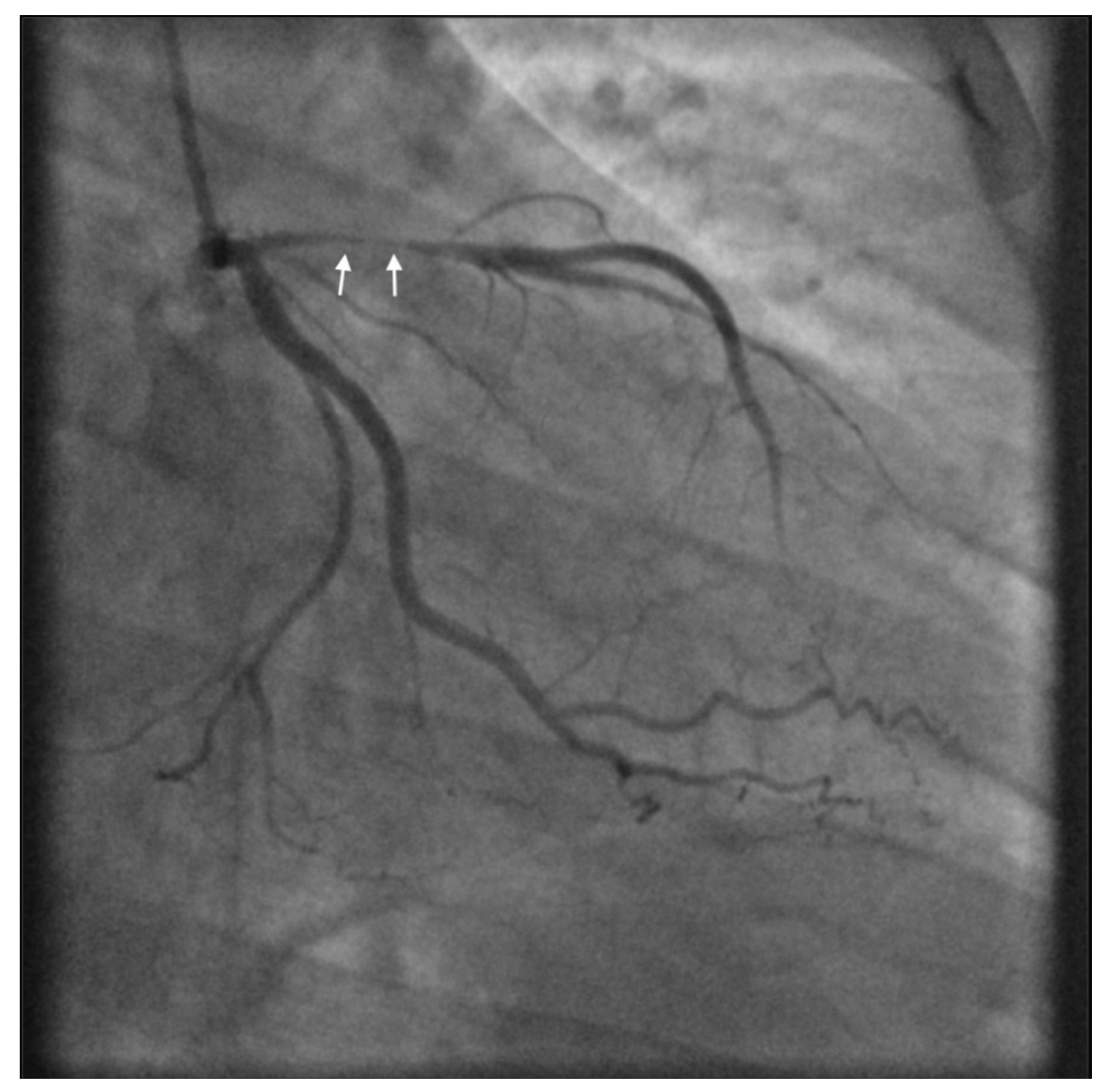

Figure 5. Coronary Angiogram of patient 2 showing a sub-occlusive focal proximal stenosis of the LAD (arrows). 


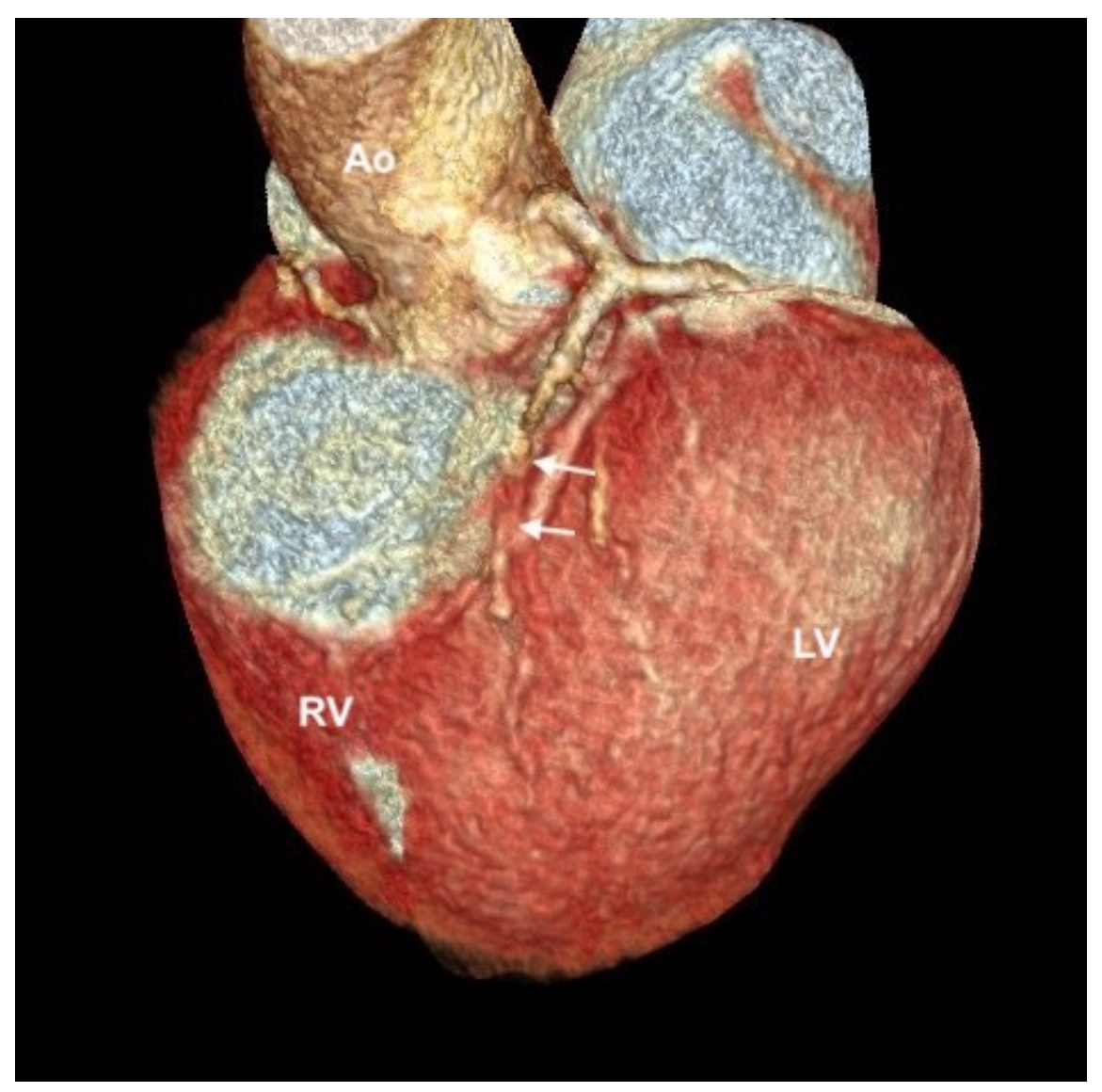

Figure 6. Computed Tomography of patient 3 showing a sub-occlusive stenosis in the mid-LAD (arrows). Ao Aorta; LV Left Ventricle; RV Right Ventricle.

\section{BIBLIOGRAPHY}

1. Rinkevich D, Kaul S, Wang XQ, Tong KL, Belcik T, Kalvaitis S, Lepper W, Dent JM, Wei K. Regional left ventricular perfusion and function in patients presenting to the emergency department with chest pain and no ST-segment elevation. Eur Heart J. 2005 Aug;26(16):1606-11. doi: 10.1093/eurheartj/ehi335. Epub 2005 May 25. PMID: 15917277.

2. Tong KL, Kaul S, Wang XQ, Rinkevich D, Kalvaitis S, Belcik T, Lepper W, Foster WA, Wei K. Myocardial contrast echocardiography versus Thrombolysis In Myocardial Infarction score in patients presenting to the emergency department with chest pain and a nondiagnostic electrocardiogram. J Am Coll Cardiol. 2005 Sep 6;46(5):920-7. doi: 10.1016/j.jacc.2005.03.076. PMID: 16139144.

3. Wei K, Peters D, Belcik T, Kalvaitis S, Womak L, Rinkevich D, Tong KL, Horton K, Kaul S. A predictive instrument using contrast echocardiography in patients presenting to the emergency department with chest pain and without ST-segment elevation. J Am Soc Echocardiogr. 2010 Jun;23(6):636-42. doi: 10.1016/j.echo.2010.03.013. Epub 2010 Apr 24. PMID: 20418056; PMCID: PMC2876194.

4. Kalvaitis S, Kaul S, Tong KL, Rinkevich D, Belcik T, Wei K. Effect of time delay on the diagnostic use of contrast echocardiography in patients presenting to the emergency department with chest pain and no S-T segment elevation. J Am Soc Echocardiogr. 2006 Dec;19(12):1488-93. doi: 10.1016/j.echo.2006.06.010. PMID: 17138034.

5. Wyrick JJ, Kalvaitis S, McConnell KJ, Rinkevich D, Kaul S, Wei K. Cost-efficiency of myocardial contrast echocardiography in patients presenting to the emergency department with chest pain of suspected cardiac origin and a nondiagnostic electrocardiogram. Am J Cardiol. 2008 Sep 15;102(6):649- 
52. doi: 10.1016/j.amjcard.2008.05.008. Epub 2008 Jul 9. PMID: 18773981; PMCID: PMC2597067.

6. Porter TR, Smith LM, Wu J, Thomas D, Haas JT, Mathers DH, Williams E, Olson J, Nalty K, Hess R, Therrien S, Xie F. Patient outcome following 2 different stress imaging approaches: a prospective randomized comparison. J Am Coll Cardiol. 2013 Jun 18;61(24):2446-2455. doi: 10.1016/j.jacc.2013.04.019. Epub 2013 May 2. PMID: 23643501.

7. Senior R, Becher H, Monaghan M, Agati L, Zamorano J, Vanoverschelde JL, Nihoyannopoulos P, Edvardsen T, Lancellotti P; EACVI Scientific Documents Committee for 2014-16 and 2016-18; EACVI Scientific Documents Committee for 2014-16 and 2016-18. Clinical practice of contrast echocardiography: recommendation by the European Association of Cardiovascular Imaging (EACVI) 2017. Eur Heart J Cardiovasc Imaging. 2017 Nov 1;18(11):1205-1205af. doi: 10.1093/ehjci/jex182. PMID: 28950366.

8. Porter TR, Mulvagh SL, Abdelmoneim SS, Becher H, Belcik JT, Bierig M, Choy J, Gaibazzi N, Gillam LD, Janardhanan R, Kutty S, Leong-Poi H, Lindner JR, Main ML, Mathias W Jr, Park MM, Senior R, Villanueva F. Clinical Applications of Ultrasonic Enhancing Agents in Echocardiography: 2018 American Society of Echocardiography Guidelines Update. J Am Soc Echocardiogr. 2018 Mar;31(3):241-274. doi: 10.1016/j.echo.2017.11.013. PMID: 29502588. 